Review

\title{
The Abiotic Depletion Potential: Background, Updates, and Future
}

\author{
Lauran van Oers ${ }^{\dagger, *}$ and Jeroen Guinée ${ }^{\dagger}$ \\ Faculty of Science Institute of Environmental Sciences (CML) - Department of Industrial Ecology, \\ Leiden University, P.O. Box 9518, Leiden 2300, RA, The Netherlands \\ * Correspondence: oers@cml.leidenuniv.nl; Tel.: +31-(0)71-527-5640 \\ + These authors contributed equally to this work. \\ Academic Editors: Damien Giurco and Mario Schmidt \\ Received: 17 December 2015; Accepted: 23 February 2016; Published: 2 March 2016
}

\begin{abstract}
Depletion of abiotic resources is a much disputed impact category in life cycle assessment (LCA). The reason is that the problem can be defined in different ways. Furthermore, within a specified problem definition, many choices can still be made regarding which parameters to include in the characterization model and which data to use. This article gives an overview of the problem definition and the choices that have been made when defining the abiotic depletion potentials (ADPs) for a characterization model for abiotic resource depletion in LCA. Updates of the ADPs since 2002 are also briefly discussed. Finally, some possible new developments of the impact category of abiotic resource depletion are suggested, such as redefining the depletion problem as a dilution problem. This means taking the reserves in the environment and the economy into account in the reserve parameter and using leakage from the economy, instead of extraction rate, as a dilution parameter.
\end{abstract}

Keywords: ADP; abiotic depletion potential; life cycle assessment; abiotic natural resources; elements; minerals; resource availability; scarcity; criticality; reserves

\section{Introduction}

From the beginning of the life cycle assessment (LCA) approach, the depletion of abiotic resources has been one of the impact categories taken into account in the environmental impact assessment. Natural resources are defined as an area of protection by the SETAC WIA (Society of Environmental Toxicology and Chemistry Working group on life cycle Impact Assessment) [1] and are part of the Life Cycle Impact Midpoint-Damage Framework developed by the UNEP (United Nations Environment Program)/SETAC life cycle initiative [2].

However, abiotic resource depletion is one of the most debated impact categories because there is no scientifically "correct" method to derive characterization factors [3]. There are several reasons for this: (1) abiotic depletion is a problem crossing the economy-environment system boundary, since reserves of resources depend on future technologies for extracting them; (2) there are different ways to define the depletion problem, and all can be justified from different perspectives; (3) there are different ways of quantifying a depletion definition, and none of them can be empirically verified, since they all depend on the assumed availability of, and demand, for resources in the future and on future technologies.

The debate on abiotic resource depletion and how to evaluate it has recently started again. This is partly because of the ongoing debate in the LCA community; see for example the guidelines of the International Reference Life Cycle Data System (ILCD) and the PEF, in Europe. (The ILCD Handbook on LCA aims to provide guidance for good practice in LCA in business and government. The development of the ILCD was coordinated by the European Commission and has been carried out in a broad international consultation process with experts, stakeholders, and the general public $[4,5]$. 
DG Environment has worked together with the European Commission's Joint Research Centre (JRC IES) and other European Commission services towards the development of a harmonized methodology for the calculation of the environmental footprint of products (including carbon). This methodology has been developed building on the ILCD Handbook as well as other existing methodological standards and guidance documents (ISO 14040-44, PAS 2050, BP X30, WRI/WBCSD GHG protocol, Sustainability Consortium, ISO 14025, Ecological Footprint, etc.) [6]. In addition, the debate on the criticality of resources has revived the debate on how to evaluate the use and depletion of resources by society [7-13].

In the context of the ILCD handbook on LCA, different characterization models for abiotic resource depletion have been reviewed by the LCA impact assessment community $[12,14]$. The characterization factors for abiotic resource depletion defined by Oers et al. [15] and recommended in the Dutch LCA Handbook [16], were selected as the best available operational method at present for so-called "use to availability ratio" methods [12]. However, contrary to the baseline method recommended in the Dutch LCA Handbook [16], the ILCD handbook and the PEF adopted a version of the abiotic depletion potential (ADP) that is calculated using the reserve base instead of the ultimate reserve estimations. This alternative choice was one of the reasons why the debate was resumed.

In this context it is useful to reflect on the assumptions that were made when developing the ADP and to think about possible future developments. This article aims to briefly describe the background considerations, options, and final choices made at the time of the original development (1995) and the latest update (2002) of the ADP. This description largely builds on the elaborate reporting of the original method developed by the Leiden Institute of Environmental Sciences (CML) [3,15,16].

\section{Description of the Characterization Model for ADP, Considerations, Options, and Choices}

\subsection{Fundamentals and Choices (1995-2002)}

Life cycle impact assessment (LCIA) is the phase in which the set of results of the inventory analysis - mainly the inventory table - is further processed and interpreted in terms of environmental impacts. Based on an evaluation, the different elementary flows contributing to a specific impact category are aggregated into one impact score. Thus, the core issue addressed by the characterization model for abiotic resource depletion is: how serious is the depletion of one particular natural resource in relation to that of another, and how can this be expressed in terms of characterization factors (ADPs) for these resources?

The development of the model requires many decisions to be made, which together frame the problem. This paper focuses only on the depletion problem of abiotic resource deposits $[3,15]$. The present section describes a selection of these issues and choices in more detail.

\subsubsection{Definition of the Problem}

When conducting an environmental assessment, it is debatable whether or not abiotic resource depletion should be part of the environmental impact assessment. After all, the problem mainly refers to the depletion of functions that natural resources have for the economy. One might, therefore, argue that resource depletion is basically an economic problem, rather than an environmental problem. This would imply that no separate impact category should be defined for the depletion of resources. Note that the environmental impact of the extraction process itself will, however, still be assessed through the contribution of current extraction processes to other impact categories.

Next to this, the problem of depletion of abiotic resources can still be defined in different ways, such as a decrease in the amount of the resource itself, a decrease in world reserves of useful energy/exergy, or an incremental change in the environmental impact of extraction processes at some point in the future (e.g., due to having to extract lower-grade ores or recover materials from scrap) etc. [12,16-18]. 
In Guinée and Heijungs [3] and Oers et al. [15], resource depletion was considered an environmental problem in its own right, while recognizing that views differ on this. The problem was defined as the decreasing natural availability of abiotic natural resources, including fossil energy resources, elements, and minerals.

\subsubsection{Concepts for Assessing Depletion}

How can the "decreasing availability" of a given resource be determined? In other words, what are possible indicators of resource depletion? The number of indicators that have been proposed even exceeds that of the definitions (see for an overview, for example, ILCD [12,14] and Klinglmair et al. [8]).

Many discussions focus on the dichotomy between price-based and physics-based indicators. Although the price of a resource can be regarded as a measure of its scarcity and societal value, it reflects more than just that. Prices are also influenced by the structure of particular economic markets, national social conditions reflected in labor cost, the power of mining companies with a monopoly, the costs of identifying new reserves, etc. For these reasons, prices of resources do not seem to be an appropriate indicator of depletion.

A depletion indicator could also be based on the various unique functions that resources can fulfill in materials and products. When trying to assess the availability of possible resources one would like to take into account possibilities for substitution. Oers et al. [15] undertook a preliminary exploration of taking substitution possibilities into account. However, elements and compounds may have very different potential functions, and possible shifts in potential functions in the future are very difficult to anticipate. Hence, it was concluded at the time that including substitution was not feasible in a characterization model for resource depletion. An exception was made for fossil energy carriers, as they were assumed to be fully interchangeable, particularly regarding their energy carrier function. It was therefore suggested to define a separate impact category for fossil fuels, based on their similar function as energy carriers [15]. However, this recommendation was not yet implemented in the baseline characterization factors described in the Dutch LCA Handbook [16].

Guinée and Heijungs [3] decided to base the characterization model for abiotic resource depletion on physical data on reserves and annual de-accumulation, with de-accumulation defined as the annual production (e.g., in $\mathrm{kg} / \mathrm{yr}$ ) minus the annual regeneration (e.g., in $\mathrm{kg} / \mathrm{yr}$ ) of a resource, the latter of which was assumed to be zero. In addition to this, Oers et al. decided that the implementation of substitution options (which touches upon issues of scarcity and criticality) was not (or not yet) feasible within LCA [15].

\subsubsection{Definition of Availability and Natural Stocks Versus Stocks in the Economy}

When assessing the availability of resources one can use the concept of availability in a narrow or a broad sense. Availability in the narrow sense focuses on the extraction of the resource from the stock in the environment, the primary extraction medium, whereas availability in the broad sense focuses on the presence of resources in stocks in the environment as well as the economy (geo- and anthropospheres).

Ideally based on the definition of the depletion of abiotic resources, the available resource should encompass both natural stocks and stocks in the economy. The criterion for depletion of the resource is whether the resource derived from the environment is still present and (easily) available in the stocks of materials in the economy. After all, as long as resources are still available in the economic stock after extraction, there is no depletion problem.

Guinée and Heijungs [3] and Oers et al. [15] decided to adopt the narrow definition of availability, while recognizing that, eventually, a broad sense definition would be preferable, assuming that it would be possible and practically feasible to define a proper indicator for this and that the necessary data would be available. The Discussion section below briefly introduces a preview of a possible new approach. 


\subsubsection{Types of Reserves and Definitions}

Estimates of the amounts of resources (elements, minerals, fuels) available for future generations depend on the definition of reserve that is used. When talking about the reserves of resources there might be confusion about the type of reserve being considered. The LCIA and geological community do not use the same definitions as traditionally used by leading geological institutions. Drielsma et al. [18] have compared the definitions as used by the Committee for Mineral Reserves International Reporting Standards (CRIRSCO) with definitions of reserves as used in the ADP [15] (Table 1). For better communication between both communities in the future the terminology of resources and reserves should be harmonized. Within the geological community the institutions are currently converging towards the CRIRSCO definitions. It seems logical that within the LCIA community the same terminology and definitions will be adopted.

Table 1. Types of reserves and definitions.

\begin{tabular}{|c|c|c|}
\hline \multicolumn{2}{|c|}{ Terminology } & \multirow{2}{*}{$\begin{array}{c}\text { Definition } \\
\text { A Resource/Reserve Classification for Minerals, USGS [3,20,21]. }\end{array}$} \\
\hline Oers et al. [15] & Drielsma et al. [19] & \\
\hline ultimate reserve & crustal content & $\begin{array}{l}\text { The quantity of a resource (like a chemical element or compound) that } \\
\text { is ultimately available, estimated by multiplying the average natural } \\
\text { concentration of the resource in the primary extraction media (e.g., } \\
\text { the earth's crust) by the mass or volume of these media (e.g., the mass } \\
\text { of the crust assuming a depth of e.g., } 10 \mathrm{~km} \text { ) [3]. }\end{array}$ \\
\hline $\begin{array}{l}\text { ultimately extractable } \\
\text { reserve }\end{array}$ & $\begin{array}{l}\text { extractable global } \\
\text { resource }\end{array}$ & $\begin{array}{l}\text { Those reserves that can ultimately be technically extracted may be } \\
\text { termed the "ultimately extractable reserves". This ultimately } \\
\text { extractable reserve ("extractable global resource") is situated } \\
\text { somewhere between the ultimate reserve and the reserve base }[20,21] \text {. }\end{array}$ \\
\hline reserve base & mineral resource & $\begin{array}{l}\text { Part of an identified resource that meets specified minimum physical } \\
\text { and chemical criteria relating to current mining practice. The reserve } \\
\text { base may encompass those parts of the resources that have a } \\
\text { reasonable potential for becoming economically available within } \\
\text { planning horizons beyond those that assume proven technology and } \\
\text { current economics. The reserve base includes those resources that are } \\
\text { currently economic (reserves) or marginally economic (marginal } \\
\text { reserves), and some of those that are currently subeconomic } \\
\text { (subeconomic resources) (for further definitions see the original } \\
\text { references) }[20,21] \text {. }\end{array}$ \\
\hline economic reserve & mineral reserve & $\begin{array}{l}\text { The part of the natural reserve base which can be economically } \\
\text { extracted at the time of determination }[20,21] \text {. }\end{array}$ \\
\hline
\end{tabular}

The disadvantage of the "reserve base" and "economic reserve" is that estimating the size of the reserve involves a variety of technical and economic considerations not directly related to the environmental problem of resource depletion. The estimates, however, are relatively certain, as they are based on present practice while, on the other hand, they are highly unstable as they continuously change over time. In contrast, the "ultimately extractable reserve" is more directly related to the environmental problem of resource depletion, and relatively stable over time. However, it is highly uncertain how much of the scattered concentrations of elements and compounds will eventually become available, as technical and economic developments in the far future are unpredictable.

The ultimate reserve and ultimately extractable reserve are expected to differ substantially. However, data on the ultimately extractable reserve are unavailable and will never be exactly known because of their dependence on future technological developments. Nevertheless, one might assume that the "ultimate reserve" is a proxy for the "ultimately extractable reserve", implicitly assuming that the ratio between the ultimately extractable reserve and the ultimate reserve is equal for all resource types. In reality this will not be the case, because the concentration-presence-distribution (see Figure 1) of different resources will most likely be different [15]. Hence, there is insufficient information to decide which of these reserves gives the best indication of the ultimately extractable reserve. Whilst 
we acknowledge some authors propose a mineralogical barrier as described by Skinner [22] this has not been considered in the research.

Guinée and Heijungs [3] and Oers et al. [15] adopted the "ultimate reserve" as the presumably best proxy for the "ultimately extractable reserve" in their characterization model for abiotic resource depletion. They recommended that alternative indicators be used for a sensitivity analysis, like the "reserve base", and to a lesser extent the "economic reserve".

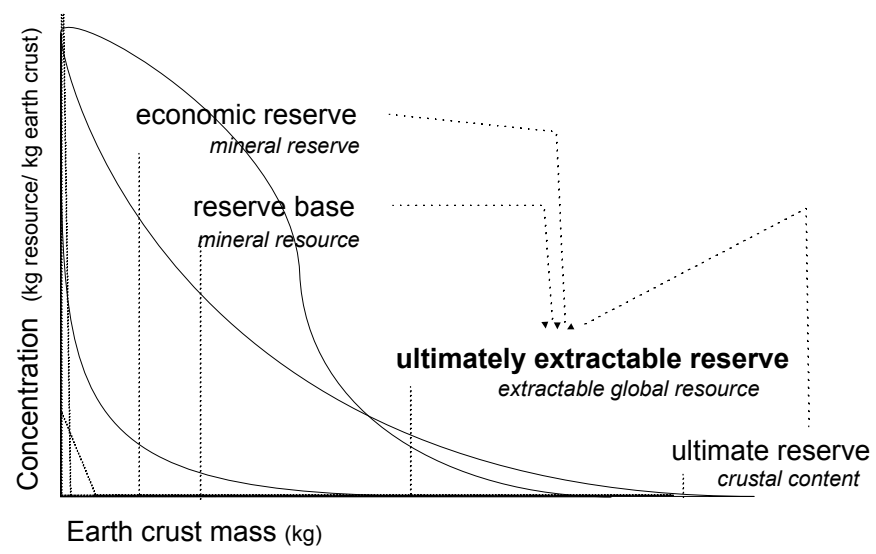

Figure 1. Concentration-presence-distribution of several theoretical resources in the Earth's crust. The average Earth crust thickness is assumed to be $17 \mathrm{~km}$. The Earth crust surface is assumed to be $5.14 \times 10^{14} \mathrm{~m}^{2}$. The average earth crust density is $2670 \mathrm{~kg} \cdot \mathrm{m}^{-3}$. The ultimate reserve of a resource is the surface area enclosed by the curve. The size of the other estimates of the reserves is given by the surface area enclosed by the curve and the given secant with the x-axis [15].

\subsubsection{Equations for Characterization Factors}

Based on all the choices described above, the characterization model can be described. The haracterization model is a function of natural reserves (stocks/deposits in the environment) of the abiotic resources combined with their rates of extraction (see Equation (2)). The method has been made operational for many elements and fossil fuels (actually: the energy content of fossil fuels). The natural reserves of these resources are based on "ultimate reserves"; that is, on concentrations of the elements and fossil carbon in the Earth's crust.

The characterization factor is the abiotic depletion potential (ADP). This factor is derived for each extraction of elements and fossil fuels and is a relative measure, with the depletion of the element antimony as a reference (see Equation (2)).

In accordance with the general structure of the LCIA, the impact category indicator result for the impact category of "abiotic depletion" is calculated by multiplying LCI results, extractions of elements and fossil fuels (in $\mathrm{kg}$ ) by the characterization factors (ADPs in $\mathrm{kg}$ antimony equivalents/kg extraction, The choice of the reference substance is arbitrary. Choosing another reference will not change the relative sizes of the characterization factors. Antimony was chosen as a reference substance because it is the first element in the alphabet for which a complete set of necessary data (extraction rate and ultimate reserve) is available, and aggregating the results of these multiplications in one score to obtain the indicator result (in kg antimony equivalents) (see Equation (1)):

$$
\text { abiotic depletion }=\sum_{i} A D P_{i} \times m_{i}
$$

with:

$$
A D P_{i}=\frac{D R_{i} /\left(R_{i}\right)^{2}}{D R_{r e f} /\left(R_{r e f}\right)^{2}}
$$


where,

$A D P_{i}$ : abiotic depletion potential of resource i ( $\mathrm{kg}$ antimony equivalents $/ \mathrm{kg}$ of resource $\mathrm{i}$ );

$m_{i}$ : quantity of resource i extracted $(\mathrm{kg})$;

$R_{i}$ : ultimate reserve of resource $\mathrm{i}(\mathrm{kg})$;

$D R_{i}$ : extraction rate of resource $\mathrm{i}\left(\mathrm{kg} \cdot \mathrm{yr}^{-1}\right)$ (regeneration is assumed to be zero);

$R_{r e f}:$ ultimate reserve of the reference resource, antimony $(\mathrm{kg})$;

$D R_{\text {ref }}$ : extraction rate of the reference resource, Rref $\left(\mathrm{kg} \cdot \mathrm{yr}^{-1}\right)$.

The first operational set of ADPs was developed by Guinée [3]. In 2002, these ADPs were updated by Oers et al. [15]. This update included new extraction rates (DRs) of resources for the base year 1999. To facilitate sensitivity analysis, alternative ADPs were developed based on different definitions of reserves, viz. economic reserve, reserve base and ultimate reserve. Oers et al. [15] adjusted the ADPs of fossil fuels and defined a separate impact category for fossil fuels based on the assumption that fossil fuels are mutually substitutable as energy carriers. However, in the LCA handbook [16], fossil fuels and elements were still considered to be part of one impact category, "abiotic resource depletion". The split into two separate impact categories was implemented in 2009.

\subsection{Developments after 2002}

Since 2002, the ADPs have been reported in a spreadsheet together with characterization factors for other impact categories. The Centrum voor Milieuwetenschappen Leiden Impact Assessment (CMLIA) spreadsheet with impact assessment factors as recommended by the Dutch LCA Handbook [16] can be downloaded from the CMLIA website [23].

2.2.1. Update of Impact Categories by CML: Impact Category of "Abiotic Resource Depletion" Split into Two Separate Impact Categories

In 2009, the impact category of "abiotic resource depletion" was split into two separate impact categories:

- "abiotic resource depletion-elements"; and

- "abiotic resource depletion-fossil fuels".

The impact category for elements is a heterogeneous group, consisting of elements and compounds with a variety of functions (all functions being considered of equal importance). The resources in the impact category of fossil fuels are fuels like oil, natural gas, and coal, which are all energy carriers and assumed to be mutually substitutable. As a consequence, the stock of the fossil fuels is formed by the total amount of fossil fuels, expressed in Megajoules (MJ).

Despite the fact that uranium is also an energy carrier, the extraction of uranium is classified under the impact category of "abiotic resource depletion-elements" and not together with the fossil fuels, under the impact category of "abiotic resource depletion-energy carriers". Uranium and fossil fuels also have other applications besides "energy carrier". Fossil fuels are considered to be interchangeable for these other applications, like the production of plastics, while uranium is not. However, one might argue that the largest application of both fossil fuels and uranium is that of an energy carrier, and for this reason they should be classified under the same impact category. Future versions of the CMLIA might be adapted accordingly.

\subsubsection{Update of ADP Values by CML}

In 2009, the ADPs reported in the Dutch Handbook on LCA [16], based on Guinée [3], were updated using the ADPs reported by Oers et al. [15] (R and DR data based on 1999 data). Since 2009, the basic data underlying the ADPs and, thus, the ADPs themselves, have not been updated anymore. 


\subsubsection{Update of $R$ and DR Values by Others}

Some new DR and R data have been reported by Frischknecht et al. [24]. However, ADPs derived from these data have not been implemented in the CMLIA spreadsheet.

Until 2010, the US Geological Survey (USGS) [20] reported the extraction rates, (economic) reserve, and reserve base data for many resources on an annual basis. However, the reserve base data have no longer been reported since 2010 .

\section{Discussion and Possible New Approaches in Abiotic Resource Depletion in CMLIA}

\subsection{Depletion, Scarcity, and Criticality}

When trying to assess the "sustainability" of the use of resources by society, different definitions of the problem of the resource use are used in terms of depletion, scarcity, and criticality.

Depletion of a resource means that its presence on Earth is reduced. This refers to geological (or natural) stocks. Scarcity of a resource means that the amount available for use is, or will soon be, insufficient ("demand higher than supply flow"). Criticality of a resource means that it is scarce and, at the same time, essential for today's society. In addition to environmental aspects, criticality assessment often also considers economic, social, and geopolitical issues [9].

Interest in natural resources has recently increased, due to the growing interest in policies to ensure the security of supply of critical metals like tantalum, indium, neodymium, etc. [10,11]. It should be noted, however, that this assessment of the criticality of metals is often based on more criteria than environmental issues alone. The criticality of a metal is based on a mixture of environmental, geopolitical, social, and economic considerations. Furthermore, the criticality debate does not necessarily take into account the cradle-to-grave chain perspective; it often only focuses on a supply of elements at the company or national economy level.

It is our opinion that the environmental impact assessment of LCA should not strive to take into account all these different aspects of criticality assessment, i.e., environment, economy, and social aspects. They may be part of a broader life cycle sustainability assessment (LCSA), but even then a general approach will be difficult, as many of the criticality aspects are highly time- and region-dependent and even differ for different stakeholders. LCSA is a framework for (cradle-to grave) system analysis which, besides environmental aspects, may also focus on economic and social issues [25,26]. However, the impact categories for "abiotic resource depletion" only deal with the environmental pillar of the sustainability assessment, and the indicator is based on the problem of depletion only.

\subsection{Ultimate Reserve, Reserve Base, and Economic Reserve}

The ADPs developed by Guinée [3] and Oers et al. [15] are based on ultimate reserves as calculated from the average element concentrations in the Earth's crust [27] assuming a crust mass of $2.31 \times 10^{22} \mathrm{~kg}$ (average depth of the earth's crust $(\mathrm{m}): 17,000$; average density $\left(\mathrm{kg} / \mathrm{m}^{3}\right): 2670$; surface of the Earth $\left.\left(\mathrm{m}^{2}\right): 5.1 \times 10^{14}\right)[3]$.

Drielsma et al. [19] stated that "crustal content" (a synonym of ultimate reserve) is a stable, comprehensive dataset that can be used to derive a physical estimate of resource depletion for abiotic resources. They base this conclusion on a study by Rudnick and Gao [28], which compared several studies done since the initial study by Clarke and Washington [29] on estimates for the total stock of resources. The study by Rudnick and Gao [28] provided updated figures on crustal content that can be used for updated ADPs based on ultimate reserves.

Given the fact that estimates of economic reserves are far less stable due to technological changes and economic developments, and that reserve base data are no longer provided by USGS [20], the use of "ultimate reserves" as a basis for the calculation of ADPs seems justified and confirmed.

We, therefore, argued here that the ILCD-recommended characterization model for abiotic resource depletion [12] based on Oers et al. [15] should be readjusted to the original reserve definition, involving ultimate reserve, instead of reserve base. 


\subsection{Availability in the Broad Sense, ADP Based on Stocks in Environment and Economy}

Resources are not only produced from natural resource supplies, but are also recycled from the growing amount of stocks in the economy and wastes ("urban stocks"). Should these stocks of materials in the economy, which can potentially be recycled, be included when estimating the total amount of available resources? In other words, should the reserve be based on the natural reserve only or also on the reserve in the economy?

As discussed above, resources fulfill specific unique functions in materials and products. Theoretically, there is no depletion problem as long as the resource after extraction is still available in the economic stock. As a consequence, resource availability should encompass both natural stocks and stocks in the economy [15].

Schneider et al. [30] made preliminary attempts to derive ADPs based on stocks in both the economy and the environment, the so-called anthropogenic stock-extended abiotic depletion potential (AADP). Their first results emphasize the relevance of anthropogenic stocks for the assessment of abiotic resource depletion. However, a larger set of characterization factors and further research are needed to verify the applicability of the concept within LCA practice. [30]. The AADPs were updated in 2015, including an approach to the estimation of the ultimately extractable reserves from the environment. The update resulted in 35 operational AADPs [31]. However, gathering information on anthropogenic stocks still remains a challenge.

The problem could therefore be redefined as follows: abiotic resource depletion is the decrease in the availability of resources, both in the environment and the economy.

\subsection{Emissions from Economic Stocks and Processes as an Indicator of Dilution}

If we adopt the broader definition of reserve described above, the de-accumulation parameter "DR" in the ADP equation becomes meaningless. After all, the extraction (DR) of resources from environmental sources for use in the economy is just a shift from environmental stock to economic stock. Thus, when redefining the reserve parameter $(\mathrm{R})$ in the ADP model, the other parameter in the model, the "extraction rate" (DR) should also be redefined.

As originally suggested by Oers et al [15], the emission of resources to the environment, instead of the extraction rate, might be a promising parameter for use in the characterization model. Oers et al. [15] suggested that the loss of resources from economic processes and stocks due to emissions of elements and compounds to air, water, and soil can be used as a measure of the dilution of resources. The argumentation is that when environmental and economic stocks are regarded as a total reserve of resources, the problem of depletion is in fact a dilution problem (see Figure 2). The assumption is that the resources that are emitted to the environment are too diffuse to be ultimately extractable and, thus, are not part of the ultimately extractable reserve. Hence, abiotic resource depletion can also be redefined as a problem of dilution of resources; that is, a reduction of concentrated reserves of resources.

Frischknecht (in: Vadenbo et al. [7]) also suggested focusing on the role of borrowing and dissipative resource use in impact assessment of abiotic resources. Material resources on Earth cannot be lost (unless converted into energy or lost into space) but might be dispersed. The impact assessment factors derived by Frischknecht are still based on the original ADP model (using environmental reserves only), but extraction rates are applied to the dissipative use of resources, which is defined as the difference between the amounts of resources extracted and recycled, i.e., the aggregated amount lost during manufacture, use, and end-of-life treatment. This new concept of assessing the dissipative use of resources using ADP factors is recommended by the new version of the ecoscarcity method [24].

Oers et al. [15] suggested a different elaboration of the characterization model for the dilution problem of resources. If depletion of abiotic resources is defined as the dilution of the resources, the leakage (L) of elements, minerals, and energy (heat) from the economy is suggested as a parameter for the characterization model, as an alternative to the extraction rate (DR). This leakage of resources can then be combined with the total reserve of resources in the environment and the economy $($ Rtotal $=\operatorname{Renv}+\operatorname{Rec})$ into a new characterization model for the dilution of abiotic resources. This new 
model can still use the original ADP equation, but the parameter extraction rate (DR) is replaced by Leakage $(\mathrm{L})$, and the reserve parameter $(\mathrm{R})$ refers to reserves in both the economy and the environment. Making these new characterization factors operational requires an estimation of stocks of elements in the economy and the total emissions of elements to the environment in the world. A preliminary approach to estimating these stocks can be based on the method and data described by Schneider [30,31] and the United Nations Environment Program (UNEP) (stocks per capita) [9]. The total emissions in the world can be based on the inventories made to derive normalization factors, as in the work by Wegener Sleeswijk et al. [32].

The result for the impact category of "abiotic resource dilution" can then be calculated by multiplying the emission, instead of extraction, of elements (in $\mathrm{kg}$ ) by the characterization factors (ADPs in $\mathrm{kg}$ antimony equivalents $/ \mathrm{kg}$ emission) and by aggregating the results of these multiplications in one score to obtain the indicator result (in $\mathrm{kg}$ antimony equivalents).

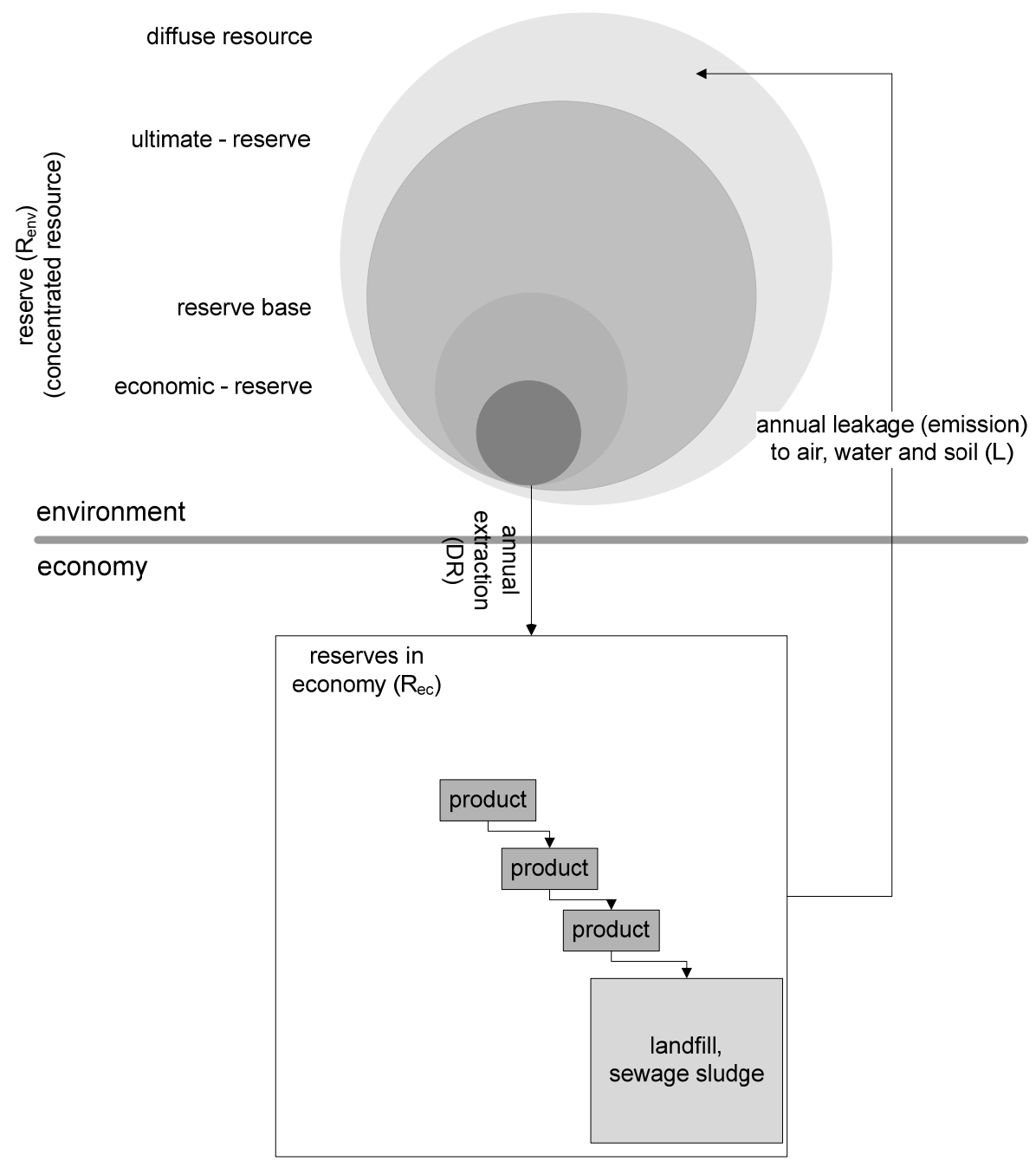

Figure 2. Relevant parameters for the abiotic resource depletion model, reserves in economy and environment and annual extraction or emission of the resource (adapted from [15]).

\section{Conclusions}

It is impossible to define one correct method for assessing the problem of depletion of abiotic resources, since the choice of relevant parameters that make up the model will depend on the problem definition, and the correctness of the parameters cannot be verified empirically. 
However, the definition of the problem and the choices made to define the characterization model will result in different sets of characterizations.

The model of abiotic resource depletion as defined in the ADP $[3,15]$ is a function of the annual extraction rate and geological reserve of a resource.

In the model as presently defined, the ultimate reserve is considered the best estimate of the ultimately extractable reserve and also the most stable parameter for the reserve parameter. However, data for this parameter will by definition never be available. As a proxy, we suggest the ultimate reserve (crustal content).

Extraction rates and reserves are regularly updated by USGS [19], partly as a result of changes in technology and new insights. As a consequence, characterization factors should also be regularly updated, but this is unfortunately no longer being done.

The impact category of abiotic resource depletion as defined by CML $[3,15]$ comprises only the depletion of environmental resources. Criticality of resources is not part of the problem definition. We recommend not including criticality in environmental LCA, as it deals with more than just environmental aspects. It could be included in the broader LCSA framework, which also tries to incorporate economic and social assessment into life cycle thinking.

A possible new development for the characterization model defined by Oers $e t$ al. [15] is the redefinition of resource depletion as a dilution problem. This implies the inclusion of reserves in the economy into the reserve parameter and using leakage from the economy, instead of extraction rate, as a dilution parameter. However, this idea remains to be worked out, and no operational characterization factors are as yet available.

Acknowledgments: Part of the development of the ADP is based on the project "Abiotic resource depletion in LCA; Improving characterization factors for abiotic resource depletion as recommended in the new Dutch LCA handbook". This project was commissioned by the Dutch Ministry of Infrastructure and the Environment.

Conflicts of Interest: The authors declare no conflict of interest. The sponsors had no role in the design of the study; in the collection, analysis, or interpretation of data; in the writing of the manuscript; or in the decision to publish the results.

\section{Abbreviations}

The following abbreviations are used in this manuscript:

AADP anthropogenic stock extended abiotic depletion potential

ADP abiotic depletion potential

CML Centrum voor Milieuwetenschappen Universiteit Leiden (Institute of Environmental Sciences, Leiden University)

CMLIA Centrum voor Milieuwetenschappen Universiteit Leiden Impact Assessment

CRIRSCO Committee for Mineral Reserves International Reporting Standards

DR extraction rate of resource, originally defined as annual de-accumulation, with de-accumulation defined as the annual extraction (e.g., in $\mathrm{kg} / \mathrm{yr}$ ) minus the annual regeneration (e.g., in $\mathrm{kg} / \mathrm{yr}$ ) of a resource, the latter of which is assumed to be zero

ILCD International Reference Life Cycle Data System

LCA life cycle assessment

LCIA life cycle impact assessment

LCSA life cycle sustainability assessment

PEF product environmental footprint

$\mathrm{R} \quad$ reserve of resource

SETAC Society of Environmental Toxicology and Chemistry

UNEP United Nations Environment Program

USGS United States Geological Survey

WIA Working Group on Life Cycle Impact Assessment 


\section{References}

1. Udo de Haes, H.A., Jolliet, O., Finnveden, G., Hauschild, M., Krewit, W., Müller-Wenk, R. (Eds.) Best available practice regarding impact categories and category indicators in life cycle impact assessment. Int. J. Life Cycle Assess. 1999, 4, 167-174.

2. Jolliet, O.; Muller-Wenk, R.; Bare, J.; Brent, A.; Goedkoop, M.; Heijungs, R.; Itsubo, N.; Pena, C.; Pennington, D.; Potting, J.; et al. The LCIA midpoint-damage framework of the UNEP/SETAC life cycle initiative. Int. J. Life Cycle Assess. 2004, 9, 394-404. [CrossRef]

3. Guinée, J.; Heijungs, R. A proposal for the definition of resource equivalency factors for use in product Life-Cycle Assessment. Environ. Toxicol. Chem. 1995, 14, 917-925. [CrossRef]

4. European Commission. ILCD Handbook, General Guide for Life Cycle Assessment_Detailed Guidance; European Commission: Ispra, Italy, 2010. Available online: http://publications.jrc.ec.europa.eu/repository/bitstream/ JRC48157/ilcd_handbook-general_guide_for_lca-detailed_guidance_12march2010_isbn_fin.pdf (accessed on 29 February 2016).

5. European Commission. European Platform on Life Cycle Assessment. 2015. Available online: http:// eplca.jrc.ec.europa.eu/?page_id=86 (accessed on 29 February 2016).

6. European Commission. Environmental Footprint News. 2016. Available online: http://ec.europa.eu/ environment/eussd/smgp/ef_news.htm (accessed on 29 February 2016).

7. Vadenbo, C.; Rørbech, J.; Haupt, M.; Frischknecht, R. Abiotic resources: New impact assessment approaches in view of resource efficiency and resource criticality-55th Discussion Forum on Life Cycle Assessment, Zurich, Switzerland, April 11, 2014. Int. J. Life Cycle Assess. 2014, 19, 1686-1692. [CrossRef]

8. Klinglmair, M; Sala, S.; Brandão, M. Assessing resource depletion in LCA: A review of methods and methodological issues. Int. J. Life Cycle Assess. 2014, 19, 580-592.

9. Van der Voet, E. Criticality and abiotic resource depletion in life cycle assessment. In Security of Supply and Scarcity of Raw Materials. Towards a Methodological Framework for Sustainability Assessment; Mancini, L., De Camillis, C., Pennington, D., Eds.; European Commission: Luxemburg, 2013; pp. 21-23.

10. United Nations Environment Programme. Environmental Risks and Challenges of Anthropogenic Metals Flows and Cycles. 2013. Available online: http://www.unep.org/resourcepanel/Publications/ EnvironmentalChallengesMetals/tabid/106142/Default.aspx (accessed on 29 February 2016).

11. European Commission. Critical raw materials for the EU; Report of the Ad-hoc Working Group on defining critical raw materials; European Commission: Brussels, Belgium, 2010. Available online: http:/ / ec.europa.eu/growth/sectors/raw-materials/specific-interest/critical/index_en.htm (accessed on 29 February 2016).

12. European Commission. In ILCD handbook: Recommendations for Life Cycle Impact Assessment in the European context-Based on Existing Environmental Impact Assessment Models and Factors; European Commission, Joint Research Centre, Institute for Environment and Sustainability: Ispra, Italy, 2011. Available online: http:/ / publications.jrc.ec.europa.eu/repository/handle/JRC61049 (accessed on 29 February 2016).

13. European Commission. Report on Critical Raw Materials for the EU; European Commission: Brussels, Belgium, 2014. Available online: http:/ /ec.europa.eu/growth/sectors/raw-materials/specificinterest/critical/index_en.htm (accessed on 29 February 2016).

14. European Commission. Analysis of existing Environmental Impact Assessment methodologies for use in Life Cycle Assessment; European Commission, Joint Research Centre, Institute for Environment and Sustainability, 2010. Available online: http://eplca.jrc.ec.europa.eu/uploads/ILCD-Handbook-LCIABackground-analysis-online-12March2010.pdf (accessed on 29 February 2016).

15. Van Oers, L.; De Koning, A.; Guinée, J.B.; Huppes, G. Abiotic resource depletion in LCA. Improving characterisation factors for abiotic resource depletion as recommended in the new Dutch LCA handbook. RWS-DWW: Delft, The Netherlands, 2002. Available online: http://www.leidenuniv.nl/cml/ ssp/projects/lca2/report_abiotic_depletion_web.pdf (accessed on 29 February 2016).

16. Guinée, J.B.; Gorée, M.; Heijungs, R.; Huppes, G.; Kleijn, R.; de Koning, A.; van Oers, L.; Wegener Sleeswijk, A.; Suh, S.; Udo de Haes, H.A.; et al. Handbook on Life Cycle Assessment: Operational Guide to the ISO Standards; Kluwer Academic Publisher: Dordrecht, The Netherlands, 2002. Available Online: http:/ / www.leidenuniv.nl/cml/lca2/index.html (accessed on 29 February 2016). 
17. Finnveden, G. "Resources" and related impact categories. In Towards a Methodology for Life Cycle Impact Assessment; Udo de Haes, H.A., Ed.; SETAC-Europe: Brussels, Belgium, 1996.

18. Heijungs, R.; Guinée, J.; Huppes, G. Impact Categories for Natural Resources and Land Use; CML-report 138; Leiden University: Leiden, The Netherlands, 1997.

19. Drielsma, J.A.; Russell-Vaccari, A.J.; Drnek, T.; Brady, T.; Weihed, P.; Mistry, M.; Perez Simbor, L. Mineral resources in life cycle impact assessment-Defining the path forward. Int. J. Life Cycle Assess. 2016, 21, 85-105. [CrossRef]

20. United States Geological Survey. Commodity Statistics and Information, Statistics and information on the worldwide supply of, demand for, and flow of minerals and materials essential to the U.S. economy, the national security, and protection of the environment. 2015. Available online: http:/ / minerals.usgs.gov/minerals/pubs/commodity/ (accessed on 29 February 2016).

21. United States Geological Survey. Appendix of Commodity Statistics and Information, Statistics and information on the worldwide supply of, demand for, and flow of minerals and materials essential to the U.S. economy, the national security, and protection of the environment A Resource/Reserve Classification for Minerals. 2015. Available online: http://minerals.usgs.gov/minerals/pubs/mcs/2007/mcsapp07.pdf (accessed on 29 February 2016).

22. Skinner, B.J. Exploring the resource base. In Proceedings of the workshop on "The Long-Run Availability of Minerals", Washington, DC, USA, 22-23 April 2001; Available online: http://www.rff.org/files/ sharepoint/WorkImages/Download/RFF-Event-April01-keynote.pdf (accessed on 29 February 2016).

23. CML-IA Characterisation Factors. Available online: https://www.universiteitleiden.nl/en/research/ research-output/science/cml-ia-characterisation-factors (accessed on 29 February 2016).

24. Frischknecht, R.; Büsser Knöpfel, S. Swiss Eco-Factors 2013 according to the Ecological Scarcity Method. Methodological fundamentals and their application in Switzerland. Environmental studies No. 1330. Federal Office for the Environment: Bern, Switzerland, 2013; p. 254. Available online: http:/ /www.bafu.admin.ch/ publikationen/publikation/01750/index.html?lang=en (accessed on 29 February 2016).

25. UNEP-SETAC. Towards a Life Cycle Sustainability Assessment. Making informed choices on products. 2011. Available online: http://www.unep.org/pdf/UNEP_LifecycleInit_Dec_FINAL.pdf (accessed on 29 February 2016).

26. UNEP-SETAC. Life Cycle Sustainability Assessment. 2015. Available online: http:/ /www.lifecycleinitiative.org/ starting-life-cycle-thinking/life-cycle-approaches/life-cycle-sustainability-assessment/ (accessed on 29 February 2016).

27. Lide, D.R., Ed.; CRC Handbook of Chemistry and Physics, 71st ed.; CRC Press: Boston, MA, USA, 1990.

28. Rudnick, R.L.; Gao, S. Composition of the continental crust. In The Crust; Rudnick, R.L., Ed.; Elsevier: Philadelphia, PA, USA, 2005; Volume 3, pp. 1-64.

29. Clarke, F.W.; Washington, H.S. The Composition of the Earth's Crust; USGS Professional Paper 127; USGS: Washington, DC, USA, 1924; p. 117.

30. Schneider, L.; Berger, M.; Finkbeiner, M. The anthropogenic stock extended abiotic depletion potential (AADP) as a new parameterisation to model the depletion of abiotic resources. Int. J. Life Cycle Assess. 2011, 16, 929-936. [CrossRef]

31. Schneider, L.; Berger, M.; Finkbeiner, M. Abiotic resource depletion in LCA-background and update of the anthropogenic stock extended abiotic depletion potential (AADP) model. Int. J. Life Cycle Assess. 2015, 20, 709-721. [CrossRef]

32. Wegener Sleeswijk, A.; van Oers, L.F.C.M.; Guinée, J.B.; Struijs, J.; Huijbregts, M.A.J. Normalisation in product life cycle assessment: An LCA of the global and European economic systems in the year 2000. Sci. Total Environ. 2008, 390, 227-240. [CrossRef] [PubMed]

(C) 2016 by the authors; licensee MDPI, Basel, Switzerland. This article is an open access article distributed under the terms and conditions of the Creative Commons by Attribution (CC-BY) license (http:/ / creativecommons.org/licenses/by/4.0/). 